\title{
An Analysis of Digital Literacy Skills among Thai University Seniors
}

\author{
$\underline{\text { http://dx.doi.org/10.3991/ijet.v11i03.5301 }}$ \\ Piatip Phuapan, Chantana Viriyavejakul and Paitoon Pimdee \\ King Mongkut's Institute of Technology Ladkrabang, Bangkok, Thailand
}

\begin{abstract}
Digital literacy and the associated skills are becoming the basic and essential skill set of any employer that wishes to survive in a highly competitive world.Given the global importance of these skills for many sectors including education, medicine, information technology, tourism, etc., the researchers sought to determine which digital literacy skills were most important in using digital technology, communications tools, and/or networks to access, manage, integrate, evaluate, create and communicate information in order to function in a knowledge society.From a multistage random sampling survey of $\mathbf{4 0 0}$ second semester university seniors finishing their degrees in 2014 at 9 Thai public and private universities, it was determined that the ability to evaluate was the most important skill indicator in the development of digital literacy. Analysis was conducted by use of LISREL 8.72.
\end{abstract}

Index Terms - skill indicators, higher education, Bloom's Digital Taxonomy, digital competency, AEC.

\section{INTRODUCTION}

It has been asserted that that one in two jobs today will no longer exist by 2025 [1] and that many of today's jobs did not exist 10 years ago. Who would have thought 10 years ago about becoming an Uber driver, a big-data miner or a mobile phone app developer?

Change is now constant; education must prepare students for that new reality. The jobs of the future will require innovation, creativity, social intelligence and high productivity; all keyed to digital literacy skills. Building up a highly skilled workforce is high on the agenda for most countries, as jobs are expected to change with greater adoption of technology and automation [2].

According to Cornell University, digital literacy is the "ability to find, evaluate, utilize, share, and create content using information technologies and the Internet' [3]. This means that the ability to complete simple tasks on a computer is just as much a part of digital literacy as high-spec skills.Also, digital literacy entails learning 'the rules of the road' of appropriate conduct with regard to copyright, plagiarism, research, and privacy-core topics that compose digital literacy [4].

Institutions also need to prepare their students for a high-stress world that demands speed and flexibility. Working from nine to five, with clearly defined targets and well- established procedures, will disappear as "cybermation" occurs which will converge innovation, human capital and technology.

Yet many students globally do not have the critical digital literacy skills they need for learning, such as keyboarding and word processing, visual mapping, and online communication. Education needs to be re-focused on lessons that cover real-life applications of spreadsheet, presentation and image editing tools, as well as how to effectively search the web and collaborate online. Students must be able to thrive in online schools, flipped classroom or blended learning environments which all requires students to have digital literacy skills.

All around the world educators, institutions, private enterprises and governments see the need. Many are rushing to develop and implement plans, which to some nations could mean economic survival. From major OECD (Organisation for Economic Co-operation and Development)educational systems, we find the following case studies concerning digital literacy initiatives that are underway:

\section{A. In the United Kingdom}

The United Kingdom Government suggests that digital abilities are fast becoming the basic skill set of any employee in any sector [5] and are becoming essential to all industries. In early 2015, the House of Lords' Digital Skills Committee published a 1,100 page report stating that digital skills should be turned into a core subject at the same level as numeracy and literacy [6].

In another report from the United Kingdom's House of Lords [7] on the U.K.'s digital future, it was emphasized how "the digital revolution is changing the labor market fundamentally". As technology becomes an increasingly integral part of everyday life, its role within the job market grows ever more important. The UK digital market has boomed in the last few years, with $15 \%$ of UK companies formed in 2013-2014 operating in the digital market. Bearing this in mind, it should be no surprise that IT skills are the most requested by job advertisers. In the future, recruiters will require not just a constant stream of digital natives; they will also need candidates with advanced digital knowledge.

Go ON UK, a UK-based charity that promotes digital skills produced a 'Digital Exclusion Heatmap' and has warned that over 12 million people lack the knowledge to prosper in the digital era. One funder is the media giant the BBC, which also supports the 'Make It Digital as well as other wider digital literacy initiatives. The research has given fresh insight into what is referred to as 'Basic Digital Skills' [8].

According to the map, in Wales one third of the population is falling behind in digital literacy. At the same time, $20 \%$ of people living in London, home to "Tech City", are not tech-literate. The Science Council has estimated that the number of people working in the information and communications technology sector will rise by $39 \%$ by 2030. Needless to say, it will become ever-more imperative to keep up with digital natives in a growing ITfocused job market. 


\section{B. In the European Union}

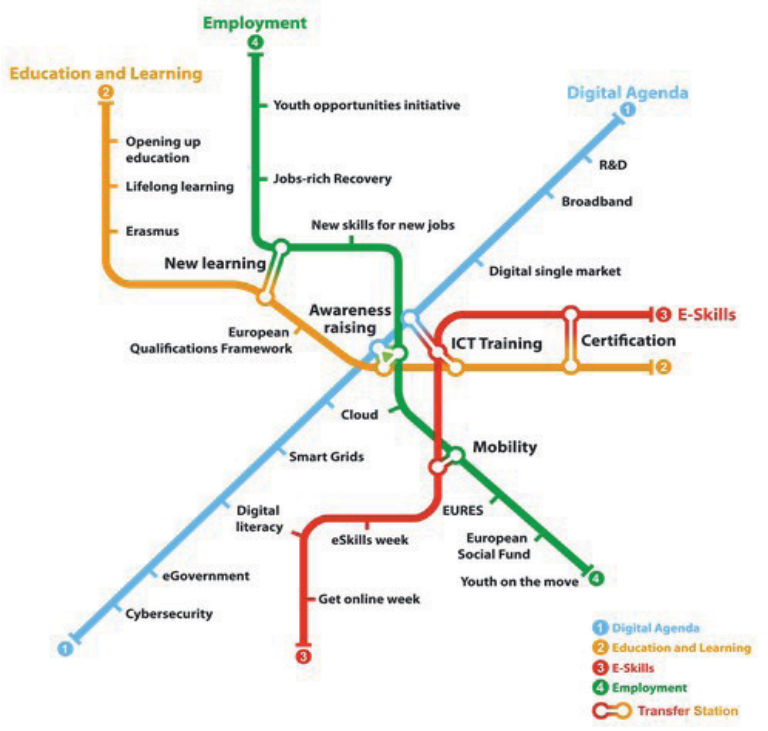

Figure 1. The Grand Coalition for Digital Jobs Network Map [9].

In 2013 the European Commission launched the Grand Coalition for Digital Jobs: a multi-stakeholder partnership that endeavors to facilitate collaboration among business and education providers, public and private actors to take action attracting young people into ICT education, and to retrain unemployed people. They have stated that $90 \%$ of jobs might require basic digital skills in careers such as engineering, accountancy, nursing, medicine, art, architecture, and many more [9].

Furthermore, the Grand Coalition for Digital Jobs stated that digital technology is transforming almost every aspect of our public, private or work life. For every individual the worker, the learner, and the citizen - the natural consequence of technological innovation is the quest for new types of skills (Fig. 1). Yet skills development does not come about as fast as technological development, which is why we are faced with a paradoxical situation: although millions of Europeans are currently without a job companies have a hard time finding skilled digital technology experts. As a result, there could be up to 825,000 unfilled vacancies for ICT (Information and Communications technology) professionals by 2020 .

\section{In Australia}

In the 2015 17th annual report card from the Foundation for Young Australians (FYA) [10] which examined how young people are faring in the transition from school to work and how well they are prepared for the future economy, it was stated that while $75 \%$ of the jobs of the future will involve Science, Technology, Engineering and Maths (STEM), 35\% of 15 year olds are not proficient in science, $42 \%$ are not proficient in maths, and $35 \%$ are not proficient in technology.

In fact, proficiency in math, science and reading is getting worse and Australia is falling in international ratings. The story is no better when it comes to digital literacy. Around $90 \%$ of jobs of the future will require digital literacy, yet $35 \%$ of 15 year olds are not digitally literate.

\section{In the United States}

On the US east coast, Comcast is working to end the digital divide, announcing that Baltimore will be the first
Internet Essentials Learning Zone in the U.S. state of Maryland. The company is providing free $\mathrm{WiFi}$ and grant money for digital literacy training to 16 community centers [11].

The U.S. Department of Housing and Urban Development (HUD) has established the 'ConnectHome' project which seeks to connect 275,000 families in 28 cities across the U.S. with the focus being on providing access to Internet, computer devices and digital literacy skills [12].

\section{LITERATURE REVIEW}

\section{A. Information, digital and media literacy become interchageable}

Digital literacy was first defined by Paul Gilster in 1997 and was stated to be; "Digital Literacy is the ability to understand and use information in multiple formats from a wide variety of sources when it is presented via computers "[13].

In this early definition information literacy and digital literacy are interchangeable, except that the latter would refer to these skills occurring through the context of digital technologies.

Later Palfrey and Gasser[14] stated the digital generation began with children who were born in or after 1980 as they were the first generation that embraced digital media and technology as part of their knowledge management process. It was further stated that even though students can develop knowledge management skills when utilizing digital technology, this generation lacks collaborative learning among them. When information 'overload' occurs, students cannot effectively organize, analyze, or synthesize information [15].

A few years later the researchers discovered that the word 'competence' had entered the literature and according to the European Parliament and the European Council in 2006, the importance of 'digital competence' was being discussed. From these bodies, recommendations on 8 key competences for lifelong learning evolved for all individuals in a knowledge-based society and a key measure in Europe's response to globalization and the shift to a knowledge-based society.

Digital competence was defined as follows [16]: "Digital competence involves the confident and critical use of information Society technology (IST) for work, leisure, learning and communication. It is underpinned by basic skills in ICT: the use of computers to retrieve, access, store, produce, present and exchange information, and to communicate and participate in collaborative networks via the Internet."

Competences were defined as a combination of knowledge, skills and attitudes appropriate to the context. Key competences were those which all individuals needed for personal fulfilment and development, active citizenship, social inclusion and employment. One of these eight key competences was 'digital competence' [16].

While all of the key competences were deemed equally important and inter-related, competence in the fundamental basic skills of language, literacy, numeracy and information and communication technologies were described as an essential foundation for learning which was subsequently be adopted into the Thai Qualifications Framework for Higher Education (TQF: HEd) [17]. 
At this point the reader might be somewhat confused about the terminology being used in these discussions. This however has been an ongoing dilemma for others as well and in the study from Ilomäki, Kantosaloand Lakkala[18]which asked 'What is digital competence?', the authors stated in a footnote that "In this paper, we have used research and policy papers that use also digital literacy or information literacy when these are used as synonym to digital competence because it is not yet a common term."

In a report from the International ICT Literacy Panel [19], it was determined that there were five critical components of ICT (Information Computer Technology) or digital literacy. The five components represent a set of skills and knowledge presented in a sequence that suggests increasing cognitive complexity. After discussions regarding the kinds of tasks represented by each component, the panel agreed on the following definitions:

- Access - knowing about and knowing how to collect and/or retrieve information.

- Manage - applying an existing organizational or classification scheme.

- Integrate - interpreting and representing information. It involves summarizing, comparing and contrasting.

- Evaluate - making judgments about the quality, relevance, usefulness, or efficiency of information.

- Create - generating information by adapting, applying, designing, inventing, or authoring information.

It is also interesting to note that this panel was convened in the earlier days of the discussion on digital literacy by the largest English language testing service in the world; ETS from Princeton, N.J. Subsequent to this panel discussion, although originally missing, 'communicate' was later added to the matrix and was used for this study as a skill indicator.

Many tools for education have been created by technology. In light of the rapid and continual development of digital technology, individuals are required to use a growing variety of technical, cognitive, and sociological skills in order to perform tasks and solve problems in digital environments. These skills are referred to in the literature as "digital literacy" [20].

Ferrari [21] stated that Digital Competence can be broadly defined as the confident, critical and creative use of ICT to achieve goals related to work, employability, learning, leisure, inclusion and/or participation in society. It was also stated that in order to be able to fill the digital competence gap, it is necessary to understand and define what digital competence is. For the study, 21 core digital competences were identified. They included the following:

1. Information: identify, locate, retrieve, store, organize and analyze digital information, judging its relevance and purpose.

2. Communication: communicate in digital environments, share resources through online tools, link with others and collaborate through digital tools, interact with and participate in communities and networks, crosscultural awareness.

3. Content-creation: Create and edit new content (from word processing to images and video); integrate and re- elaborate previous knowledge and content; produce creative expressions, media outputs and programming; deal with and apply intellectual property rights and licenses.

4. Safety:personal protection, data protection, digital identity protection, security measures, safe and sustainable use.

5. Problem-solving:identify digital needs and resources, make informed decisions as to which are the most appropriate digital tools according to the purpose or need, solve conceptual problems through digital means, creatively use technologies, solve technical problems, update one's own and others' competences.

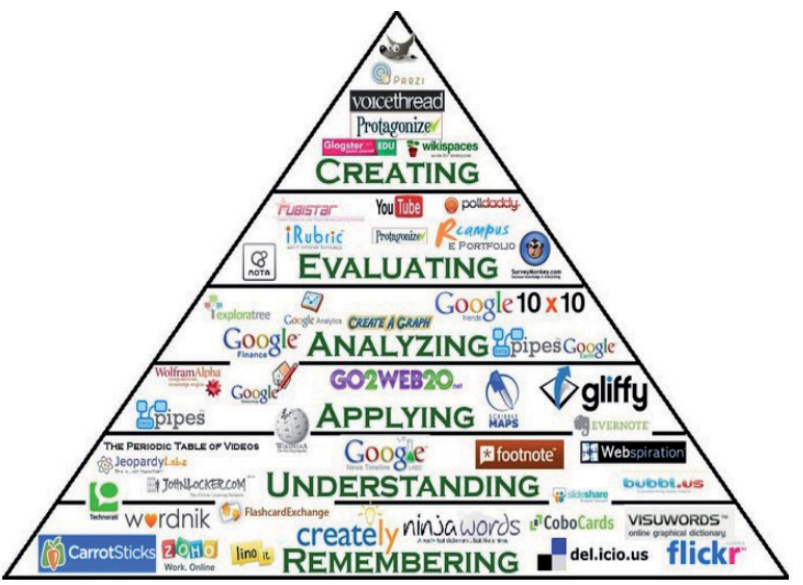

Figure 2. Web 2.0 Tools[22] based on Bloom's Digital Taxonomy[23]

Today in a highly modified version of the 1956 'Bloom's Taxonomy', a Web 2.0 'digital generation' model for digital literacy skills and tools is depicted in Fig. 2 [22].

In it can be seen 'creating' at the top of the pyramid, which in Bloom's first model 'Evaluation' was placed at the peak of the pyramid. 'Evaluation' in 1956 being defined as the ability to assess, grade, recommend, judge, decide, test, convince, support, rank, measure, select, and conclude [23].

The framework elaborated by Bloom and his collaborators consisted of six major categories: Knowledge, Comprehension, Application, Analysis, Synthesis, and Evaluation. The categories after Knowledge were presented as "skills and abilities," with the understanding that knowledge was the necessary precondition for putting these skills and abilities into practice. While each category contained subcategories, all lying along a continuum from simple to complex and concrete to abstract, the taxonomy is popularly remembered according to the six main categories which has been the framework applied by generations of educators in their teaching [24].

Today, the Thai Qualifications Framework for Higher Education (TQF: HEd) is an education qualification system adapted from The National Qualification Framework adopted by the United Kingdom and Australia [17]. The Thai TQF is used to standardize the quality of education in Thailand with the expected learning outcomes of students in five domains, namely: ethical and moral development, cognitive skills, interpersonal skills and responsibility, analytical and communication skills, and numerical analysis, communication and information technology [25].

With this understanding and using these frameworks, the researchers sought to further develop guidelines for 
enhancing and supporting digital literacy skills development in Thai higher education institutions and universities. It was felt that the results of the research would be beneficial to these institutions in helping identify and develop their student's digital literacy skills while helping improve their quality of life and future employment possibilities. Results could also be could be applied to digital literacy courses in areas such as computer or engineering. Moreover, the indicators for measuring skills could be applied to gauge the skills effectiveness of the institutions. Lastly, it is hoped that the results can lead to the development and improvement in promoting digital skill literacy in the future.

\section{Methodology}

\section{A. Participants}

Students for the survey consisted of Thai university seniors enrolled at 9 universities during the second semester of the 2014 school year which were located in both the Bangkok metropolitan area and outside it. In the Bangkok metropolitan area, these institutions included Mahidol University, King Mongkut's Institute of Technology Latkrabang (KMITL) near Suvarnabhumi Airport, the largest airport in Southeast Asia and hub to international tourism and trade, Silpakorn University which is a public university focused on the arts, and Kasetsart University which was the first agricultural university and the third oldest university in Thailand.

Regional institutions included Northern Thailand's second largest city's Chiang Mai University, Burapha University which is a major public university located in the coastal town of Bangsaen, Chonburi Province, KhonKaen University $(K K U)$ which was the first university established in Northeastern Thailand (Isan) and which today is the largest in the region, Phitsanulok's new and modern Naresuan University in Northcentral Thailand located only a few kilometers from the 'Indochina Intersection', and UbonRatchathani University east of Bangkok near Cambodia.

From these campus populations, the surveyed participants included $211(52.75 \%)$ male seniors and 189 $(47.25 \%)$ female students. The survey mix was highly dispersed and rich in different experiences and cultural backgrounds. Students were asked to respond to questions concerning their learning environments and their ability to adapt to Information and Computer Technology education and its use.

\section{B. Research Dimensions}

Dimension 1's synthesis (Fig. 3) was the outcome created from the research literature and papers related to digital literacy skills. The research was therefore undertaken to determine which digital literacy skills were most important in using digital technology, communications tools, and/or networks to access, manage, integrate, evaluate, create and communicate information in order to function in a knowledge society.

Dimension 2 (Fig. 3) originated from Bloom's Digital Taxonomy which included; remembering, understanding, applying, analyzing, evaluating, creating, and communication [23].

Dimension 3 depicts (Fig. 3) the adaptation from the OECD countries of the U.K. and Australia [17]. The Thai Qualifications Framework for Higher Education (TQF:
HEd) is an education qualification system which is used to standardize the quality of education in Thailand with the expected learning outcomes of students in five domains, namely: ethical and moral development, cognitive skills, interpersonal skills and responsibility, analytical and communication skills, and numerical analysis, communication and information technology [25].

The questionnaire contained 34 questions organized into groups according to Dimension 1 in Fig. 3.

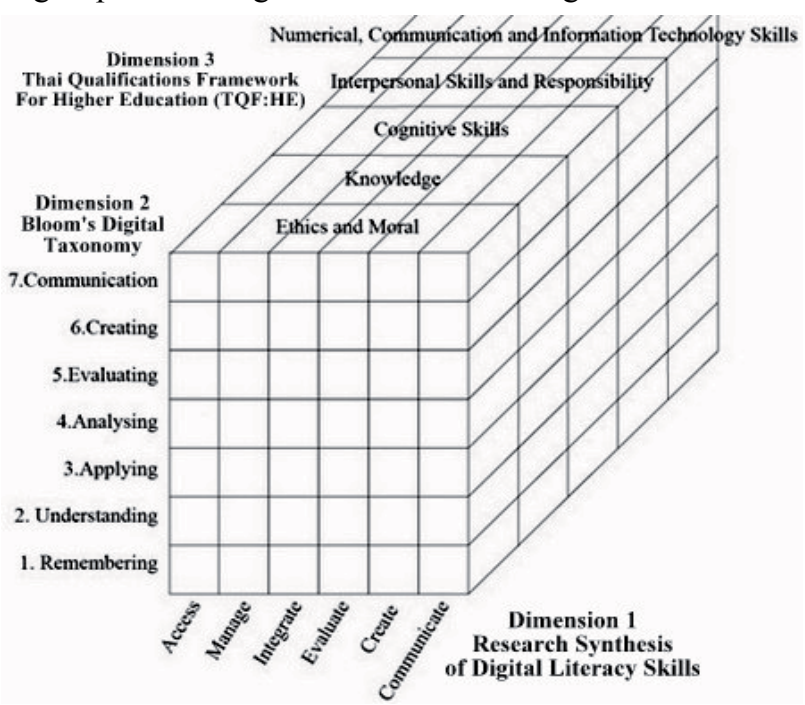

Figure 3. The multiple dimensions analyzed for the research showing the final Digital Literacy Skill Indicators synthesized for analysis in Dimension 1.

\section{Data Collection}

For this research, the measurement instrument or questionnaires utilized were prepared from the literature and previous research [26]. A self-administered questionnaire survey was collected from 400 Thai university seniors from 9 universities using a multistage, random sampling technique. The questionnaires contained the students' opinions concerning their digital literacy skills grouped into 6 skill indicator categories including which rated the importance in using digital technology, communications tools, and/or networks to 1) access, 2) manage, 3) integrate, 4) evaluate, 5) create and 6) communicate information in order to function in a knowledge society(Fig. 3). The survey questions used for each digital literacy skill indicator were as follows: Access $(A)=1-6$; Manage $(M)$ =7-11; Integrate $(\mathrm{I})=13-18$; Evaluate $(\mathrm{E})=19-24$; Create $(\mathrm{C})=25-30$; Communicate $(\mathrm{Com})=31-35$. (Note: Question 12 was deleted.)

\section{The Questionnaire}

The questionnaire was based on a 4-point Likert scale [27] as the measurement scale and the conceptual framework for determining the internal consistency measured by coefficient alpha ( $\alpha$-coefficient) of Akron BAC (Cronbach) to calculate the average value of the correlation coefficient which was considered to be highly reliable as all values lower than 0.70 were eliminated from the measurement after the update from the initial 39 query samples.

All values lower than 0.50 were eliminated from the measurement. Additionally, a bipolar scaling method consisting of $4=$ Highest, $3=$ High, $2=$ Low and $1=$ Lowest was employed which is described as an even-scale ap- 
proach which is used when the middle option of 'neither agree nor disagree' is omitted.

To gauge both the content validity and reliability of the survey, 5 experts in their respective fields were chosen to evaluate the consistency of the content and confirm it was valid for the purposes of the research.

Additionally, the index of Item-Objective Congruence (IOC) developed by Rovinelli and Hambleton [28] was employed to carry out the screening of questions. The IOC is a procedure used in test development for evaluating content validity at the item development stage. This measure is limited to the assessment of unidimensional items or items that measure specified composites of skills. The method prescribed by Rovinelli and Hambleton [28] results in indices of item congruence in which experts rate the match between an item and several constructs assuming that the item taps only one of the constructs which is unbeknownst to the experts. The research then proceeded to select items that with an IOC index higher than 0.5 which were considered acceptable.

The researchers sought to determine which digital literacy skills were most important in using digital technology, communications tools, and/or networks to access, manage, integrate, evaluate, create and communicate information in order to function in a knowledge society. From a multistage random sampling survey of 400 second semester university seniors finishing their degrees in 2014 at 9 Thai public higher education institutions.

The analysis was conducted following three steps. In the first stage, all 34 indicators generated were included in the first-order measurement model for digital literacy skills. The initial model fitness was assessed and subjected to re-specification. In the second stage, a second order confirmatory factor analysis was performed (Fig. 4) based on the re-specified model. Finally, nested models were reported to compare the accepted measurement model with other competing models.

\section{RESUlts AND DiscUSSION}

\section{A. Analysis}

An Analysis of Digital Literacy Skills among Thai University Seniorswas conducted following two steps. In the first stage, all items generated were included in the firstorder measurement model for digital literacy skills. The initial model fitness was assessed and subjected to respecification. In the second stage, a second order confirmatory factor analysis was performed based on the respecified model.

The Second Order CFA (confirmatory factor analysis) is a statistical method employed by the researchers to confirm that the theorized construct in the study loads into certain number of underlying sub-constructs or components. This revealed that the model fit the empirical data with the following: $\chi^{2}=1.136, \mathrm{df}=97, \mathrm{p}=0.169$, $\mathrm{GFI}=0.972, \mathrm{AGFI}=0.945, \mathrm{RMR}=0.016$ (Table I). The factor loading of the 6 single indicators were positive, ranging in size from $0.67-0.99$. The highest factor loading indicators was the evaluate skill (0.99).

To produce an over-identified model, the first regression path in each measurement component was fixed at 1 . The criteria used to evaluate the items were each item's error variance estimate; evidence of items needing to cross-load on more than one component factor as indicated by large modification indices; the extent to which items give rise to significant residual covariance (Table II); parsimony purpose; regression coefficient of each item; reliability of the item and the reliability of the whole construct [29]. Additionally, the logic and consistency of data with the theoretical framework was considered when evaluating each item.

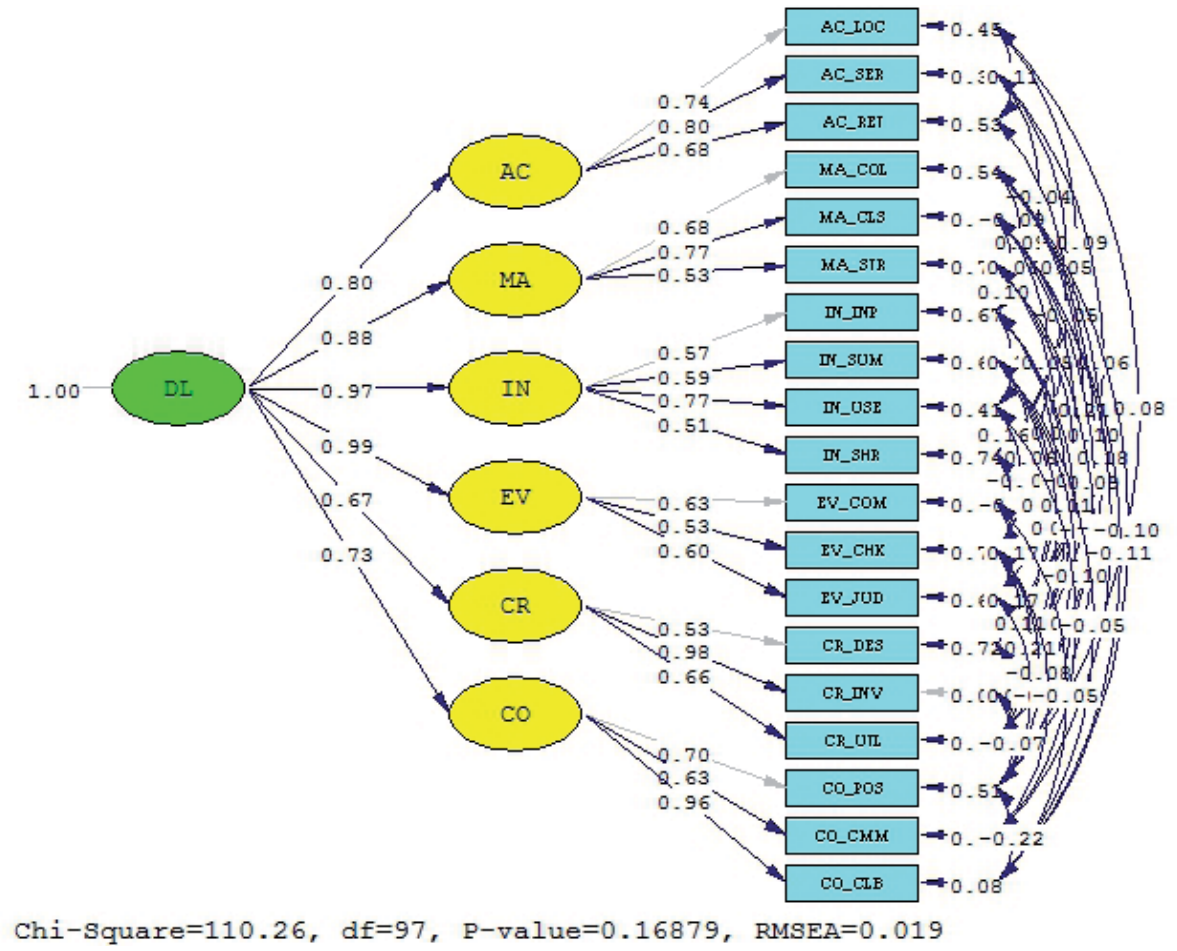

Figure 4. The Second Order Confirmatory Factors model construct of digital skills literacy indicators for Thai university seniors at 9 Bangkok metropolitan and provincial/regional universities. 
PAPER

AN ANALysis of Digital Literacy SKILls AMONG THAi UNIVERSITY SENIORS

TABLE I.

STATISTICAL FIT OF DIGITAL LITERACY SKILL INDICATORS FOR STUDENTS IN HIGHER EDUCATION PUBLIC INSTITUTES.

\begin{tabular}{c|c|c|c}
\hline Fit Statistic & Criteria & Value & Summary \\
\hline$\chi^{2} / \mathrm{df}$ & $<3.000$ & 0.136 & Pass \\
\hline p-value & $>0.050$ & 0.972 & 0.945 \\
\hline GFI & $>0.900$ & 0.988 & Pass \\
\hline AGFI & $>0.800$ & 0.016 & Pass \\
\hline NFI & $>0.900$ & 0.034 & Pass \\
\hline RMR & $<0.050$ & Pass \\
\hline RMSEA & $<0.050$ & & \\
\hline
\end{tabular}

TABLE II.

FACTOR LOADING, COVARIANCE AND RANK OF DIGITAL LITERACY SKILL INDICATORS

\begin{tabular}{|c|c|c|c|c|c|c|c|}
\hline \multirow{2}{*}{ Elements } & \multicolumn{2}{|c|}{ Factor Loading } & \multirow{2}{*}{ B } & \multirow{2}{*}{$\mathbf{t}$} & \multirow{2}{*}{$\mathbf{R}^{2}$} & \multirow{2}{*}{ FS } & \multirow{2}{*}{ Rank } \\
\hline & b & SE & & & & & \\
\hline ACCESS: AC & 0.343 & 0.027 & 0.800 & 12.664 & 0.640 & - & 4 \\
\hline Locate: AC_LOC & 1.000 & - & 0.745 & - & 0.555 & 0.157 & (2) \\
\hline Search: AC_SER & 1.071 & 0.075 & 0.797 & 14.349 & 0.635 & 0.246 & (1) \\
\hline Retrieve: AC_RET & 0.983 & 0.067 & 0.685 & 14.566 & 0.469 & 0.103 & (3) \\
\hline MANAGE: MA & 0.379 & 0.030 & 0.881 & 12.449 & 0.776 & - & 3 \\
\hline Collect: MA_COL & 1.000 & - & 0.676 & - & 0.457 & 0.160 & (2) \\
\hline Classify: MA_CLS & 1.057 & 0.082 & 0.768 & 12.965 & 0.589 & 0.203 & (1) \\
\hline Store: MA_STR & 0.788 & 0.088 & 0.534 & 9.001 & 0.286 & 0.086 & (3) \\
\hline INTEGRATE: IN & 0.387 & 0.034 & 0.969 & 11.269 & 0.938 & - & 2 \\
\hline Interpret: IN_INP & 1.000 & - & 0.573 & - & 0.329 & 0.022 & (3) \\
\hline Summarize: IN_SUM & 1.015 & 0.110 & 0.585 & 9.199 & 0.343 & 0.049 & (2) \\
\hline Use: IN_USE & 0.930 & 0.076 & 0.767 & 12.303 & 0.588 & 0.178 & (1) \\
\hline Share: IN_SHR & 0.861 & 0.102 & 0.514 & 12.303 & 0.264 & 0.028 & (4) \\
\hline EVALUATE: EV & 0.363 & 0.028 & 0.991 & 12.740 & 0.982 & - & 1 \\
\hline Compare: EV_COM & 1.000 & - & 0.634 & - & 0.402 & 0.005 & (1) \\
\hline Checking: EV_CHK & 1.073 & 0.116 & 0.525 & 9.219 & 0.276 & 0.044 & (3) \\
\hline Judge: EV_JUD & 0.946 & 0.074 & 0.602 & 12.761 & 0.363 & -0.018 & (2) \\
\hline CREATE: CR & 0.308 & 0.034 & 0.668 & 9.196 & 0.446 & - & 6 \\
\hline Design: CR_DES & 1.000 & - & 0.532 & - & 0.283 & 0.040 & (3) \\
\hline Invent: CR_INV & 1.198 & 0.097 & 0.984 & 12.409 & 0.968 & 0.849 & (1) \\
\hline Utilize: CR_UTL & 1.205 & 0.101 & 0.662 & 11.887 & 0.438 & 0.044 & $(2)$ \\
\hline COMMUNICATE: CO & 0.319 & 0.030 & 0.728 & 10.730 & $\mathbf{0 . 5 3 0}$ & - & 5 \\
\hline Post: CO_POS & 1.000 & - & 0.699 & - & 0.489 & 0.245 & (2) \\
\hline Comment: CO_CMM & 0.984 & 0.116 & 0.627 & 8.464 & 0.393 & -0.015 & (3) \\
\hline Collaborate: CO_CLB & 1.206 & 0.106 & 0.958 & 11.396 & 0.918 & 0.665 & (1) \\
\hline
\end{tabular}

Note: The development of digital literacy skill indictors found that there were 34 indictors which were statistically significant at the .01 level.

Of the 6 primary digital literacy skill indicators surveyed, 4 had 6 associated skills with 'manage' and 'communication' having only 5 .

\section{B. Discussion}

After a review of the literature two words often appeared to be used interchangeably. They were 'literacy' and 'competence'. In addition to the literature review discussion of 'literacy' and 'competency', the following is added to the discussion for further clarification and deliberation:

The US Workforce Investment Act [30] defines literacy as 'an individual's ability to read, write, speak in English, compute and solve problems at levels of proficiency necessary to function on the job, in the family of the individual and in society.' As information and technology have become increasingly shaped our society, the skills we need to function successfully have gone beyond reading, and literacy has come to include the skills listed in the current definition.

The Literacy Development Council of Newfoundland and Labrador [31] defines this term in the following: "Literacy not only involves competency in reading and writing, but goes beyond this to include the critical and effective use of these in peoples' lives, and the use of language (oral and written) for all purposes." This definition involves critical thinking about what one reads, as well as expanding the term to encompass oral forms of literacy.

And according to the OECD, a competence is more than just knowledge and skills. It involves the ability to meet complex demands, by drawing on and mobilizing psychosocial resources (including skills and attitudes) in a particular context. For example, the ability to communicate effectively is a competence that may draw on an 
individual's knowledge of language, practical IT skills and attitudes towards those with whom he or she is communicating' [32].

Therefore, according to Ferrari [33] Digital Competence is often understood as a multi-faceted competence. The conceptualization of Digital Competence in terms of multiple literacies (media literacy, information literacy, internet literacy and ICT literacy as the main literacies related to Digital Competence) has been used as a basis for searching for frameworks, in order to cover different aspects of Digital Competence. This is consistent with Ala-Mutka's 'Digital literacy and other related literacies' [34].

Others according to the literature review also felt digital competence should be considered a multi-faceted concept that emerges from several backgrounds [34], [18], [33]. It is closely related to literacy approaches but is not identical. These different notions mean there are still no clear assessment guidelines for digital competence [35]. While some perceive digital competence as the technical use of ICT, others define it more broadly as knowledge application or as 21 st century skills.

The 2015 California Emerging Technology Fund (CETF) Annual Survey 'Internet Connectivity and the "Digital Divide" in California Households: 2015' details how the lowest-income, least-educated Californians are living without an essential tool for self-sufficiency and a better quality of life [36]. ICT digital literacy as delineated in the California ICT Digital Literacy Assessments and Curriculum Framework is ability to use digital technology and communications tools, and/or networks to access, manage, integrate, evaluate, create and communicate information in order to function in a knowledge society [37].

Along the same lines in Europe a digital competence framework was developed by European Commission's JRC IPTS on behalf of DG Education and Culture. The overall aim was to contribute to the better understanding and development of European digital competence which was stated to be one of the eight key competences for lifelong learning which was essential for participation in our increasingly digitalized society [38].

\section{CONCLUSION}

Therefore it is necessary to understand and define what digital competence is and consists of as there are various aspects of digital competence differentiating it from other similar or overlapping concepts. It is also important to understand the implication of the historic evolution of the term and finally it is crucial to detail the digital competence framework in its constituting parts.

In Europe, the outcome of the research proposed a digital competence framework which consisted of 22 competences divided into 5 areas. For each competence there were multiple proficiency levels[38].

Therefore, digital literacy skill indicators are derived from the study of digital literacy and competency skills of students and this relationship found in the 5 domains of standard learning concepts from the Thai Qualifications Framework for Higher Education and mapping of the digital literacy skill indicators with Bloom's Digital Taxonomy to arrive at the study's digital indicators which were judged to be the most valuable in the use of digital technology, communications tools, and/or networks to access, manage, integrate, evaluate, create and communicate information in order to function in a knowledge society[23]. The findings indicated that the skill to 'evaluate' should be given the highest priority for development when compared to the other skills.

\section{ACKNOWLEDGMENT}

This research was funded by the Institute for the Promotion of Teaching Science and Technology, Bangkok, Thailand. We therefore would like to take this opportunity to thank them.

\section{REFERENCES}

[1] A. De Meyer, The jobs - they are a-changing. 2015. [Online]. Available: https://tinyurl.com/pxgn8uj[Accessed: 21- Nov- 2015].

[2] H.M.A. Khamid, Pursuing a vocational track - an alternative pathway to success?, Channel NewsAsia, 08 Nov 2015. [Online]. Available: https://tinyurl.com/odzgxzx_[Accessed: 21- Nov2015].

[3] Cornell, What is Digital Literacy? Cornell University. 2009. [Online]. Available: https://tinyurl.com/pwfwds8 [Accessed: 21Nov- 2015].

[4] T. Mitrano, Welcome from Tracy Mitrano, Director of Information Technology Policy in the Office of Information Technology Policies at Cornell University. 2009. [Online]. Available: https://tinyurl.com/pjkvls9 [Accessed: 21- Nov- 2015].

[5] D. Lill,Digital skills essential for future-proofing career, 5 November, 2015. [Online]. Available: https://tinyurl.com/pv7qqpd [Accessed: 21- Nov- 2015].

[6] House of Lords, Select Committee on Digital Skills - Oral and written evidence. 2015.[Online]. Available: https://tinyurl.com/ktxmuxl [Accessed: 21- Nov- 2015].

[7] House of Lords, Make or Break: The UK's Digital Future, HOUSE OF LORDS Select Committee on Digital Skills Report of Session 2014-15 published 17 February 2015. [Online]. Available: https://tinyurl.com/nwrvvcq [Accessed: 21- Nov- 2015].

[8] Go ON UK, Digital Exclusion Heatmap - Exploring exclusion from a digital United Kingdom. 2015.[Online]. Available: https://tinyurl.com/o6jw6pp [Accessed: 21- Nov- 2015].

[9] EC, Grand Coalition for Digital Jobs - European Commission. 25/09/2015.[Online]. Available: https://tinyurl.com/qeqwuxc [Accessed: 21- Nov- 2015].

[10] F.Y.A. Report Card 2015 How are Young People Faring in the Transition from School to Work? Foundation for Young Australians (F.Y.A.). 2015. [Online]. Available: https://tinyurl.com/oq4yw4u [Accessed: 21- Nov- 2015].

[11] T. Do, Baltimore leaders push for greater access to high-speed internet; Comcast launches new effort. 2015. [Online]. Available: https://tinyurl.com/pltfb3h [Accessed: 21- Nov- 2015].

[12] J. McGee, Digital inclusion push gets more attention. The Tennessean. 2015. [Online]. Available: https://tinyurl.com/o2vhwtz [Accessed: 21- Nov- 2015].

[13] T. Newman, A review of digital literacy in 3-16 year olds: evidence, developmental models, and recommendations. 2009. [Online]. Available: https://tinyurl.com/ngouy4n [Accessed: 21Nov-2015].

[14] J. Palfrey and U. Gasser, Understanding the First Generation of Digital Natives, Basic Books, N.Y. 2008. [Online]. Available: https://tinyurl.com/napbhnc [Accessed: 21- Nov- 2015].

[15] A. Calvani, A. Fini, M. Ranieri, andP. Picci, Are young generations in secondary school digitally competent? A study on Italian teenagers, Computers and Education Volume 58, Issue 2, February 2012, Pages 797-807. http://dx.doi.org/10.1016/j.compedu. 2011.10.004

[16] DG Connect, Measuring Digital Skills across the EU: EU wide indicators of Digital Competence. May 2014. [Online]. Available: https://tinyurl.com/ot2pjuo [Accessed: 21- Nov- 2015].

[17] National Qualifications Framework for Higher Education in Thailand. Implementation Handbook. November 2006. [Online]. Available: https://tinyurl.com/oyca3zl [Accessed: 21- Nov- 2015]. 
[18] L. Ilomäki, A. KantosaloandM. Lakkala, What is digital competence? 2011. [Online]. Available: https://tinyurl.com/q35d7s7 [Accessed: 21- Nov- 2015].

[19] ETS, Digital Transformation A Framework for ICT Literacy A Report of the International ICT Literacy Panel, Educational Testing Service. $2007 . \quad$ [Online]. Available: https://tinyurl.com/qan7po6 [Accessed: 21- Nov- 2015].

[20] Y. Eshet-Alkalai, "Digital Literacy: A Conceptual Framework for Survival Skills in the Digital Era”. Journal of Educational Multimedia and Hypermedia. 13(1),93-106. 2004.[Online]. Available: https://tinyurl.com/q55mgfx [Accessed: 21- Nov- 2015].

[21] A. Ferrari (Y. Punieand B.N. Brečko, ed.), DIGCOMP: A Framework for Developing and Understanding Digital Competence in Europe. Joint Research Centre, and Institute for Prospective Technological Studies. 2013. doi:10.2788/52966. [Online]. Available: https://tinyurl.com/o39snke [Accessed: 21- Nov- 2015].

[22] J. Hammond, Web 2.0 Tools Based on Bloom's Digital Taxonomy. 2011. [Online]. Available: https://tinyurl.com/od5yjcf [Accessed: 21- Nov- 2015].

[23] A. Churches, Bloom's Digital Taxonomy. 2008. [Online]. Available: https://tinyurl.com/noqm39e [Accessed: 21- Nov- 2015]

[24] P. Armstrong, Bloom's Taxonomy. 2015.[Online]. Available: https://tinyurl.com/onep4pm [Accessed: 21- Nov- 2015].

[25] P. Maneerata, K. Malaivongsb, andJ. Khlaisanga, "The Comparison of Thai Qualification Framework for Higher Education and Capability Maturity Model Integration for Service"Procedia - Social and Behavioral Sciences, Volume 182, 13 May 2015, Pages 225-23. 14th world Conference on Educational Technology Researches (WCETR-2014).[Online]. Available: https://tinyurl.com/owd6ph4 [Accessed: 21- Nov- 2015].

[26] P. Phuapan, C. Viriyavejakul, and P.Pimdee, "Digital literacy skill of students in public higher education institutes". The Asian Conference on Technology in the Classroom 2015. Conference Proceeding 2015 (207-216). Kobe, Japan. [Online]. Available: https://tinyurl.com/ptn49o7 [Accessed: 21- Nov- 2015].

[27] R. Likert, "Likert Technique for Attitude Measurement”. In: Social Psychology: Experimentation, Theory, Research, Sahakian, W.S. (Ed.). Intext Educational Publishers, Scranton, USA, ISBN-13: 9780700223879, 1972, pp: 101-119.

[28] R.J. RovinelliandR.K. Hambleton, "On the use of content specialists in the assessment of criterion-referenced test item validity". Dutch Journal for Educational Research, 2: 1979, 49-60.

[29] C.L. WangandP.K. Ahmed, "The development and validation of the organisational innovativeness construct using confirmatory factor analysis",European Journal of Innovation Management, 2004 7(4):303-313. [Online]. Available: https://tinyurl.com/ocfka26 [Accessed: 21- Nov- 2015].

[30] The Workforce Investment Act (1998). Public Law 105-220--Aug. 7, 1998112 Stat. 936. Public Law 105-220. 105th Congress. 1998.
[Online]. Available: https://tinyurl.com/ouh7335 [Accessed: 21Nov- 2015].

[31] Literacy Development Council of Newfoundland and Labrador, 2000. [Online]. Available: https://tinyurl.com/nq9wngo [Accessed: 21 - Nov- 2015].

[32] OECD, The Definition and Selection of Key competencies, Executive Summary. 2005.[Online]. Available: https://tinyurl.com/q4rkecz [Accessed: 21- Nov- 2015].

[33] A. Ferrari, Digital Competence in Practice: An Analysis of Frameworks. 2012 [Online]. Available: https://tinyurl.com/nj6eksb [Accessed: 21- Nov- 2015].

[34] K. Ala-Mutka, Mapping Digital Competence: Towards a Conceptual Understanding. 2011.[Online]. Available: https://tinyurl.com/oanp64t [Accessed: 21- Nov- 2015].

[35] K. AnaniadouandM. Claro, 21st century skills and competences for new millennium learners in OECD countries. OECD Education Working Papers, (41). 2009. http://dx.doi.org/10.1787/218525261154

[36] CETF, Internet Connectivity and the "Digital Divide" in California Households: 2015. California Emerging Technology Fund. 2015. [Online]. Available: https://tinyurl.com/qckkg3o[Accessed: 21- Nov- 2015]

[37] CETF, California ICT Digital Literacy Assessments and Curriculum Framework. California Emerging Technology Fund. 2008. [Online]. Available: https://tinyurl.com/nuwccfw [Accessed: 21Nov- 2015].

[38] A. Ferrari, B. BrečkoandP. Punie, DIGCOMP: a Framework for Developing and Understanding Digital Competence in Europe. Digital Literacies and eCompetence. ISSN: 1887-1542 May 2014. Online]. Available: https://tinyurl.com/pdv6tbv [Accessed: 21Nov- 2015].

\section{AUTHORS}

Piatip Phuapan is Ph.D. student with the Faculty of Industrial Education at King Mongkut's Institute of Technology Ladkrabang (KMITL) (poepia@gmail.com).

Chantana Viriyavejakul is Associate Professor with the Faculty of Industrial Education at King Mongkut's Institute of Technology Ladkrabang (KMITL) (kmchanta@kmitl.ac.th).

Paitoon Pimdee is Assistant Professor with the Faculty of Industrial Education at King Mongkut's Institute of Technology Ladkrabang (KMITL) (kppaitoo@kmitl.ac.th)

This research was funded by the Institute for the Promotion of Teaching Science and Technology, Bangkok, Thailand. Submitted 20 November 2015. Published as resubmitted by the authors 7 February 2016. 